\title{
O Piano Coletivo no Plano Nacional de Formação de Professores - PARFOR
}

Cinthia Ruivo

Resumo: Este artigo relata a experiência realizada com uma turma do PARFOR (Plano Nacional de Formação de Professores) na Universidade Estadual de Maringá (UEM), no exercício da Prática Instrumental - Piano Coletivo e, visa abordar as estratégias utilizadas, as etapas galgadas pelos alunos e os resultados obtidos durante o período de aplicação da disciplina.

Palavras-chave: piano coletivo; PARFOR; piano em grupo.

Abstract: This article presents the experience of a PARFOR (National Teacher Training Plan) group at the State University of Maringá (UEM), in the exercise of the Instrumental Practice - Collective Piano and, aims to address the strategies, development and results of these students during the period of application of the discipline.

Keywords: collective piano; PARFOR; piano in group.

\section{Introdução}

O curso de formação de professores (PARFOR) teve início na Universidade Estadual de Maringá no ano de 2011. A turma, aqui apresentada é a terceira na instituição, com início no ano de 2016 e finalização em novembro de 2017. Nas práticas instrumentais a grade é composta pelos seguintes instrumentos: piano, canto, violão, cujos cursos são distribuídos em quatro módulos, e flauta e percussão com cursos distribuídos em dois módulos. Neste artigo, abordaremos apenas os cursos de piano coletivo.

Trabalhar o piano coletivo com alunos que tiveram pouco ou nenhum contato com instrumentos de teclas é de certa forma, um desafio. Por conta disso, elaboramos um plano de ensino que pudesse atender a todos, colaborando com a formação e possibilitando a 
aquisição de competências para utilização do instrumento como uma ferramenta de trabalho principalmente no contexto de ensino em sala de aula.

Como professora, tive a oportunidade de trabalhar com a segunda turma (ano de 2015), dividindo a disciplina com mais dois professores e, na divisão de tarefas, minha função foi o trabalho com o processo de leitura de partitura envolvendo ditados, solfejos e, por fim, a execução no instrumento.

No ano de 2015, em reunião com o corpo docente e coordenação, sentimos a necessidade de uma alteração nas ementas do curso, visto que, as duas turmas anteriores tinham a disciplina concentrada, totalizando $160 \mathrm{~h} / \mathrm{a}$. Decidimos então, todos os professores unanimamente, que a distribuição das aulas em 4 módulos semestrais, com uma carga horária de 24 horas e com o conteúdo dividido por ordem crescente de dificuldade possibilitaria maior aproveitamento no aprendizado.

\section{O Piano Coletivo no Parfor}

O ensino coletivo de piano no PARFOR, visa a utilização do instrumento não como solista, mas como uma ferramenta para o professor no ensino de música. Segundo Cerqueira (2009), o ensino do piano coletivo pode não ser tão profundo quanto o estudo individual, mas pode proporcionar uma oportunidade para que os alunos reflitam, interajam social e emocionalmente, dividindo seus problemas, muitas vezes chegando à soluções partilhadas por todos.

O cirtério para ingresso no plano de formação de professores é possuir uma licenciatura e fazer parte da rede estadual de ensino, possibilitando que os estudantes sejam conhecedores do contexto em que atuam e das problemáticas gerais enfrentadas na educação básica. Em relação à formação musical dos alunos, na verdade não existem 
critérios, o que resulta em um grupo heterogêneo. Na turma explorada neste artigo, de um total de 16 alunos, somente 12 concluíram a disciplina e apenas 4 tinham tido contato com algum tipo de instrumento de teclado.

\section{Metodologia}

O curso foi então dividido em 4 módulos com carga horária de 24 horas aula, sempre aos sábados, com os seguintes conteúdos para cada um:

\section{Módulo 1}

Foram trabalhados elementos técnicos básicos tais como leitura das claves de sol e fá, escalas e arpejos maiores (1 oitava), campo harmônico maior, acordes, inversões e leitura por cifras. Desenvolvimento de repertório de nível básico popular (solo e em conjunto) assim como improvisação e utilização do piano como ferramenta de trabalho (um recurso sonoro). Os objetivos nesse módulo eram:

- Trabalhar o desenvolvimento da leitura de notas e cifras e de ritmos variados;

- Desenvolver a habilidade de reconhecer os graus I, IV e V (Tônica, Subdominante e Dominante) nas diversas tonalidades maiores.

- Desenvolver a consciência crítica da habilidade pianística enquanto uma ferramenta de trabalho incentivando a criatividade no processo de ensino-aprendizagem.

- Trabalhar conceitos técnicos e interpretativos do repertório pianístico popular partindo da prática cotidiana com experiências coletivas. 


\section{Módulo 2}

Desenvolvimento de escalas maiores e suas relativas menores, bem como seus respectivos arpejos, campo harmônico menor e leitura de cifras. Exploração de repertório popular. Iniciação a padrões rítmicos variados (choro, samba, tango, entre outros).

Os objetivos eram:

- Trabalhar o desenvolvimento da leitura de notas e cifras;

- Trabalhar conceitos técnicos e interpretativos do repertório pianístico popular;

- Desenvolver a habilidade de reconhecer os graus I, IV e V (Tônica, Subdominante e Dominante) nas diversas tonalidades maiores e menores e a utilização desses graus para o trabalho de acompanhamento das músicas.

\section{Módulo 3}

Desenvolvimento do campo harmônico de todas as escalas e transposição harmônica bem como a utilização no repertório. Desenvolvimento de repertório de nível intermediário (solo e grupos).

Objetivos

- Desenvolvimento da leitura dos sinais musicais (notas e cifras);

- Trabalhar conceitos técnicos e interpretativos do repertório pianístico popular;

- Realizar o campo harmônico nas diversas tonalidades e transposição harmônica;

- Trabalhar padrões rítmicos;

\section{Módulo 4}

Desenvolvimento do repertório pianístico para solo, quatro e seis mãos, dois pianos e outras formações. Aspectos de leitura à primeira vista e transposição de melodias. Improvisação a partir de estímulos diversos: imagem, poesia, temas do cotidiano e teórico-musicais.

Objetivos 
- Trabalhar o desenvolvimento da leitura de notas e cifras;

- Trabalhar conceitos técnicos e interpretativos do repertório pianístico erudito e popular;

- Trabalhar padrões rítmicos e improvisação;

- Estimular o reconhecimento de padrões sintático-estruturais na partitura;

- Refletir e vivenciar, através do piano, as perspectivas dos agentes musicais: ouvinte, intérprete e compositor.

No desenvolver do curso, mais especificadamente $3^{\circ}$ e $4^{\circ}$ módulos, houve um trabalho em conjunto com a professora de canto e, por conta disso, sentimos a necessidade de uma adaptação no cronograma. Pedimos para que cada aluno escolhesse uma música do livro "500 canções brasileiras" da Ermelinda A. Paz e criasse um arranjo para piano e voz. A maioria dos alunos fizeram o arranjo à duas vozes e, no acompanhamento, deram espaço à criatividade inserindo os ritmos que acharam convenientes. Após concluírem, ensinaram seus colegas, recriando um trabalho com os alunos em sala de aula.

Ainda no $3^{\circ}$ módulo, utilizamos a criação de arranjo em outra atividade. Dividimos a turma em 3 grupos com 4 alunos e pedimos para que cada grupo escolhesse uma música e, em seguida, sorteamos o grupo responsável pela realização do arranjo instrumental. Segue a figura para uma melhor compreensão: 


\section{Figura 1}

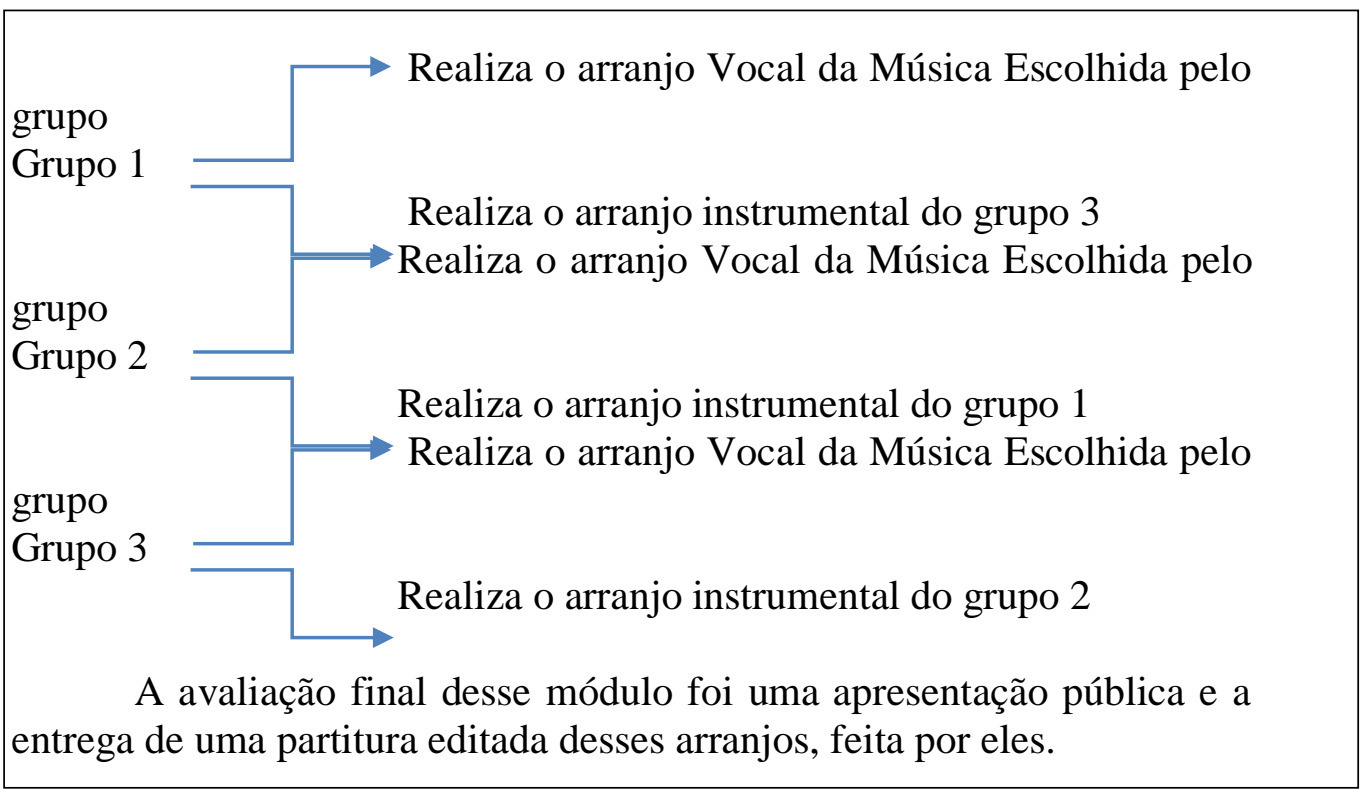

No $4^{\circ}$ e último módulo, continuamos com o trabalho proposto no cronograma mas acrescentamos uma atividade com um viés mais prático e dinâmico, para que eles colocassem em prática tudo o que haviam aprendido nos módulos anteriores. Para isso, dividimos a turma em duplas e cada uma montou um plano de aula aplicando-o em seguida aos colegas sob a supervisão das professoras.

\section{Resultados}

Após a realização de todas as atividades entregamos um questionário de auto avaliação e de avaliação do curso em geral (conteúdo, didática e professor) e, mesmo não fazendo parte do cronograma, houve a possibilidade da gravação de um CD com os arranjos individuais que haviam sido realizados no módulo 3 . Nesse questionário obtivemos as seguintes respostas: 
Aluno 1: "Acredito que nós alunos, de forma geral temos muitas lacunas em nosso aprendizado musical; precisamos nos esforçar muito além do que apenas estar presente aos sábados. Tivemos ótimas aulas para além dos conteúdos musicais, que serviram também de ideias para nossos estágios e aulas e que esclareceram muitos assuntos de outras disciplinas. Então, todos os conteúdos e didáticas foram adequados, importantes e construtivos, sobretudo no curto prazo disponível".

Aluno 2: "No piano o aprendizado foi enorme, pois sinceramente era um instrumento que eu nunca havia tocado. A partir das aulas, venho me dedicando ao estudo em casa, treinando variações de acordes e arranjos. Creio que tenho muito a melhorar e as aulas me abriram portas para o buscar, descobrir e o criar.[...] As metodologias utilizadas foram essencialmente práticas a as professoras sempre nos ajudaram quando tivemos dúvidas ou pedimos sugestões. Na disciplina foi proposta a elaboração e aplicação de planos de aula, proporcionando a criação, ou seja, experimentar e realizar uma aula prática e lúdica para o contexto da sala de aula, finalizando as disciplinas com êxito.

Aluno 3: "As aulas de piano coletivo, foram muito interessantes, pois exercitamos a montagem de arranjos tendo a chance de executálos durante as aulas, exercitando-nos em casa e aperfeiçoando assim o aprendizado. Foi possível elaborar uma construção do conhecimento pela mediação da professora o que propiciou compreensão e respeito as diferenças dos níveis de aprendizagem dos alunos durantes as aulas. Procurei ser assíduo para ampliar meu conhecimento. A união das disciplinas trouxe enriquecimento e integração das diversas formas possíveis de se trabalhar música o que favoreceu a compreensão das disciplinas. Quanto ao meu desenvolvimento pessoal acredito que aprendi muito e tenho posto em prática os conhecimentos adquiridos".

Aluno 4: "[...]quanto aos conteúdos e metodologia utilizados nas aulas considero de suma importância os conteúdos abordados e a metodologia aplicada. O desempenho das professoras foi excelente e tomo-o como exemplo." 
Aluno 5: "Os conteúdos trabalhados durante as aulas foram de suma importância para mim sendo desafiador criar arranjos vocais e instrumentais, no entanto esse trabalho coletivo foi uma forma de crescimento para meu aprendizado retroalimentando o crescimento musical pessoal. Quanto a metodologia e os conteúdos não tenho o que reclamar. Só tenho a agradecer pela paciência e dedicação para conosco. As aulas foram ministradas de forma dinâmica e com muito conteúdo."

Aluno 6: "As propostas foram desencadeadas com muito esmero pelas professoras e a metodologia nos inseriu no processo nas atividades práticas de sala de aula".

Aluno 7: "[...]Sempre busquei participar das aulas e aprender, isso me leva a crer que tive um processo de aprendizagem, não apenas como aluno, mas também como professor, principalmente no quarto módulo[...]"

Aluno 8: "O piano é o instrumento mais maravilhoso de todos, mais difícil e mais desafiador, o qual eu escolhi para me dedicar. Mas no começo a impressão que tinha era que as aulas eram planejadas e pensadas para os alunos que já tinham conhecimento. De certa forma essa impressão foi que me impulsionou a não desistir. Procurei ajuda e segui em frente. Hoje não o vejo como o instrumento mais difícil[...] Foram aulas gostosas e por ser piano coletivo, ótimas pois em cada aula surgia novas descobertas e avanços."

Aluno 9: "No Piano gostei muito da "Marcha Imperial" neste último módulo e muitas outras músicas trabalhadas durante toda a disciplina. Acredito que para mim seja mais fácil perceber as evoluções no piano, pois através de um treinamento constante, de repetição, percebo os resultados positivos[...] Achei muito interessante a proposta de trabalho com os arranjos, porque foi fonte de muito crescimento. Era algo que parecia muito distante, quase inalcançável na minha cabeça. Mas depois, conseguir realizar um arranjo de uma música foi muito gratificante. Ao final quando foi proposto cifrar as músicas, achei que foi muito relevante, porque haverá momentos em nossa prática na escola 
que isso será muito útil, pois trabalhamos com realidades variadas e precisamos estar aptos a fazer arranjos das músicas adequando-as a cada contexto. Haverá muito estudo pela frente, mas vi que é possível. "

Aluno 10: "Quanto ao Piano Coletivo, já estudei alguns anos em conservatórios, onde o ensino é individualizado, isso fez com que eu demorasse um tempo para adaptar-me com o método de Ensino Coletivo de Piano o que considero ter sido um obstáculo para que eu não atingisse o resultado que esperava [...] Os conteúdos abordados foram bastante significativos e acredito que muito contribuíram para com meu processo de formação musical, as metodologias utilizadas foram bastante eficaz, a escolha das músicas foram muito assertivas e o trabalho de arranjos foi muito bem pensado e muito válidos."

Aluno 11: "De acordo com os conteúdos abordados neste módulo, tive um grande avanço em questão as leituras das partituras, acordes e com grande aprendizado nas atividades de composição. Tenho certa dificuldade ainda em questão a harmonia, o que faz com que continue meus estudos em casa mesmo tendo terminado nossa disciplina. A metodologia utilizada nas aulas no qual tivemos que aplicar aulas de composição foi um aprendizado sim, porém senti falta do ensino por parte de vocês professoras já que teu conhecimento é muito amplo e senti falta de explorar um pouco mais desse conhecimento para meu trabalho, ou seja, poderíamos ter aprendido bem mais com você do que com nossos colegas de turma".

Aluno 12: Não participou da aula e não respondeu o questionário. Levando em consideração as respostas dos alunos podemos observar que, na maioria, a metodologia utilizada foi de grande importância para o grupo pois fez surgirem ideias para a aplicação na sala de aula, como afirmaram os alunos:

"[...]os conteúdos musicais serviram também de ideias para nossos estágios e aulas[...]"(ALUNO 1) 
“[...]proposta a elaboração e aplicação de planos de aula, nos oportunizando criar, experimentar e realizar uma aula prática e lúdica para o contexto da sala de aula[...]" (ALUNO 2)

[...]a metodologia nos inseriu no processo nas atividades práticas de sala de aula[...]"(ALUNO 6)

"[...]tive um processo de aprendizagem, não apenas como aluno, mas também como professor[...]" (ALUNO 7)

Outro ponto forte destacado pelos alunos foi o trabalho realizado com arranjo. Segundo eles:

"[...]prática de montar arranjos e executá-los durante as aulas[...]". (ALUNO 3)

“"Os conteúdos trabalhados durante as aulas foram de suma importância para mim sendo desafiador criar arranjos vocais e instrumentais, no entanto esse trabalho coletivo foi uma forma de crescimento para meu aprendizado retroalimentando o crescimento musical pessoal[...]"(ALUNO 5)

"[...]proposta de trabalho com os arranjos, porque foi de muito crescimento. Era algo que parecia muito distante, quase inalcançável na minha cabeça. Mas depois, conseguir realizar um arranjo de uma música foi muito gratificante[...]". (ALUNO 9)

[...] o trabalho de arranjos foi muito bem pensado e muito válidos" (ALUNO 10)

Sendo assim, baseado nos comentários dos alunos, podemos observar que, dentro da grande gama de possibilidades que abordam o ensino do piano coletivo, a utilização do arranjo, como criação/execução é, para o PARFOR, a atividade de maior importância pois, é possível, dentro das possibilidades estruturais da rede pública de ensino, fazer um trabalho com música. 


\section{Conclusão}

Por se tratar de um programa de formação de professores, o perfil dos alunos é o do profissional atuante na rede pública de ensino e que por conta disso buscam materiais e metodologias que os auxiliam no ensino em sala de aula. No entanto, por não existir critérios de conhecimento musical, o caráter totalmente heterogêneo da turma possibilitou um trabalho coletivo direcionado com arranjos que exigiam diferentes níveis de conhecimento, indo do básico até ao nível intermediário, o que exige que o professor de música esteja sempre atento ao objetivo pedagógico que sua disciplina propõe. Sendo assim, o processo de introdução (módulos 1 e 2) para os alunos que não tinham nenhum conhecimento do instrumento foi produtivo e equilibrado com os demais que já sabiam tocar um pouco, possibilitando a conclusão dos módulos seguintes com êxito.

\section{Referências}

CERQUEIRA, Daniel Lemos. O arranjo como ferramenta pedagógica no ensino coletivo de piano. Música Hodie, volume 9, $\mathrm{n}^{\circ} 1$, P. 129-140, 2009.

CRUVINEL, Flávia Maria. O Ensino Coletivo de Instrumentos Musicais na Educação Básica: compromisso com a escola a partir de propostas significativas de Educação Musical. Meio eletrônico, 2008. Disponível em file:///C:/Users/User/Downloads/Ensino\%20Coletivo\%20de\%20Instr\%20 Musical\%20na\%20Escola.pdf

FLACH, Gisele Andrea. Arranjos para piano em grupo: um estudo sobre as decisões, escolhas e alternativas pedagógico-musicais. Dissertação de mestrado. Universidade Federal do Rio Grande do Sul. Porto Alegre, 2013. 
SCARAMBONE, Denise; MONTANDON, Isabel. A reflexão do professor de piano sobre sua prática pedagógica: uma introdução. Encontro anual da Associação Brasileira de Educação Musical XVII, Anais, P. 1-7, 2008. 